University of Nebraska - Lincoln

DigitalCommons@University of Nebraska - Lincoln

\title{
Winter Feeding Sites of Hay in Round Bales as Major Developmental Sites of Stomoxys calcitrans (Diptera: Muscidae) in Pastures in Spring and Summer
}

\author{
Alberto B. Broce \\ Kansas State University \\ Jerome Hogsette \\ USDA-ARS-CMAVE, Jerry.Hogsette@ars.usda.gov \\ Steven Paisley \\ Kansas Agricultural Extension Service
}

Follow this and additional works at: https://digitalcommons.unl.edu/usdaarsfacpub

Part of the Agricultural Science Commons

Broce, Alberto B.; Hogsette, Jerome; and Paisley, Steven, "Winter Feeding Sites of Hay in Round Bales as Major Developmental Sites of Stomoxys calcitrans (Diptera: Muscidae) in Pastures in Spring and Summer" (2005). Publications from USDA-ARS / UNL Faculty. 1014.

https://digitalcommons.unl.edu/usdaarsfacpub/1014

This Article is brought to you for free and open access by the U.S. Department of Agriculture: Agricultural Research Service, Lincoln, Nebraska at DigitalCommons@University of Nebraska - Lincoln. It has been accepted for inclusion in Publications from USDA-ARS / UNL Faculty by an authorized administrator of DigitalCommons@University of Nebraska - Lincoln. 


\title{
Winter Feeding Sites of Hay in Round Bales as Major Developmental Sites of Stomoxys calcitrans (Diptera: Muscidae) in Pastures in Spring and Summer
}

\author{
ALBERTO B. BROCE, JEROME HOGSETTE, ${ }^{1}$ AND STEVEN PAISLEY ${ }^{2,3}$ \\ Department of Entomology, Kansas State University, Manhattan, KS 66506-4004
}

J. Econ. Entomol. 98(6): 2307-2312 (2005)

\begin{abstract}
The stable fly, Stomoxys calcitrans (L.), historically has been a pest of livestock in confined operations but seldom of animals on pastures or rangelands. In the past two decades, however, S. calcitrans has become a major pest of cattle and horses on pastures in the midwestern United States. Although there usually is an overabundance of diverse stable fly and house fly, Musca domestica L., larval habitats in confined livestock operations, no larval habitat for stable flies has been clearly identified in the pasture-range environment. Because the winter feeding of hay in round bales results in significant amounts of hay wastage that when mixed with manure, might develop into suitable larval habitats, this study evaluated these areas as developmental sites for the abundant stable flies in pastures. There was a trend for fly traps placed in the vicinity of hay feeding sites to catch more stable flies than those placed distant from these sites. Estimates of stable flies emerging from these sites ranged from 102 to 1225 flies per core sample $(25$ by $25 \mathrm{~cm}$ ). The mean number of adult stable flies during May and June 2001 through 2004 correlated negatively with the average minimum temperatures during the preceding winter (November-February) but not with rainfall or temperatures during the spring. These results support the hypothesis that winter feeding sites of hay in round bales are the main source of stable flies in pastures.
\end{abstract}

KEY WORDS stable flies, hay, larval habitats, round bales

The STABLE FLY, Stomoxys calcitrans (L.), has long been known to be serious pests of cattle in confined animal feeding operations (CAFO), such as dairies (Bruce and Decker 1958) and feedlots (Campbell et al. 1987), where larval habitats for these flies abound. The effects of stable flies on weight gain performance of feedlot cattle have received special attention by Campbell and coworkers in Nebraska (Campbell et al. 1987). In the past two decades, stable flies also have become important pests of cattle and horses in pastures in the midwestern United States. Hall et al. (1982) reported large numbers of stable flies attacking pastured cattle in Missouri, numbers much larger than observed previously. Entomologists, producers, and veterinarians also have reported stable fly problems on grazing cattle in North Dakota, South Dakota, Wyoming, Colorado, Nebraska, and Kansas. When attacked by stable flies, both confined and pastured cattle react by attempting to protect their front legs, which are the main feeding sites. Cattle do this by bunching, or lying with their legs tucked beneath their

\footnotetext{
${ }^{1}$ USDA-ARS-CMAVE, P.O. Box 14565, Gainesville, FL 32604

${ }^{2}$ Kansas Agricultural Extension Service, South Central Area, Hutchinson, KS 67505.

${ }^{3}$ Current address: Department of Animal Sciences, University of Wyoming, Laramie, WY 82071
}

bodies, tail switching, foot stomping, or standing in water (Campbell et al. 1977). It is reasonable to assume that stable flies' effects on weight gain performance of pastured cattle are similar to those observed on feedlot cattle, although this has only been documented in one study, because of the lack of effective stable fly control on pastured animals. In that study, Campbell et al. (2001) recorded a reduced average daily gain of $0.23 \mathrm{~kg} / \mathrm{d}$ in $84-\mathrm{d}$ trials, when control animals were protected from stable flies by topical application of pesticides at least three times per week.

Stable flies develop in decaying organic matter, particularly if mixed with manure and soil. Thus, Meyer and Petersen (1983) found that spilled feed, stored manure, and all forms of silage were major larval habitats in Nebraska feedlots. In eastern Nebraska feedlots, feed aprons, where manure, bedding material, and feeding wastes accumulate, produced more stable fly larvae than any other habitat (Skoda et al. 1991). Broce (1993) demonstrated that compost piles, especially those containing grass clippings, are ideal habitats for stable flies in urban backyards. Although house flies preferentially colonize fresh cattle manure, stable flies prefer older ( $>2$-wk-old) manure (Broce and Haas 1999).

Considerable information is available on stable fly larvae developing in habitats in CAFO, but relatively 


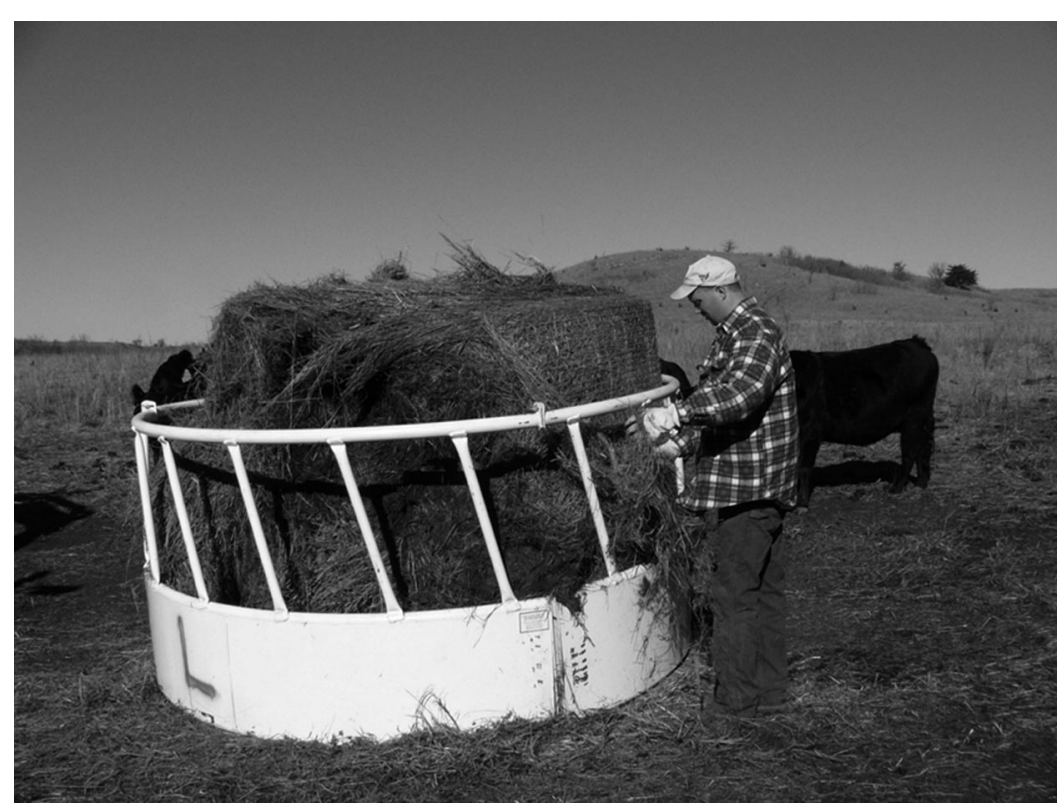

Fig. 1. Conventional type of tub feeder or ring feeder for use with round bales.

little is known about their development in pastures and range environments. It is well known that these flies do not colonize undisturbed cowpats (Hogsette et al. 1987). Hall et al. (1982) found numerous stable fly larvae developing at the edge of the big round hay bales stored in the field in Missouri. Larvae were most numerous if the hay was wet and had been stored in the field for any length of time, but there is no evidence that these round bales are a significant source of stable flies in western Nebraska (J. Campbell, personal communication) and central Kansas (A.B.B., unpublished). Nevertheless, there are numerous other potential habitats for stable fly larvae that heretofore have gone unnoticed in midwestern pastures. One of these, hay wasted by cattle fed large bales in winter, represents the most obvious stable fly larval habitat in the spring. Patterson and Morgan (1986) estimated 28,000 larvae per $\mathrm{m}^{2}$ in hay residues at a dairy in northwestern Florida. Residues may remain active larval sites for a long time and become very thick, especially if new bales continue to be placed at the same feeding place. The rise of stable fly populations in pastures in the United States parallels recently reported increases of stable flies developing in cane bagasse at sugarcane plantations in South Africa and in plant residues at pineapple and coffee plantations in Central America, and in poultry litter used as fertilizer in vegetable production in Perth, western Australia (www.agric.wa.gov.au/ento/bitter2.htm). Because hay wasted by cattle feeding from the large bales has been considered in recent times to be the most obvious stable fly larval habitat in pasture environments, this study was undertaken to determine the importance of these sites.

\section{Materials and Methods}

Nine sites where hay had been fed during winter $2000-2001$ were used for this study during spring 2001. These sites were located in pastures neighboring Manhattan, KS, in Riley and Pottawatomie counties. At eight of these sites, round bales of native grasses had been fed by using conventional tub or ring feeders (2.3-2.7 $\mathrm{m}$ in diameter, Fig. 1); at the remaining site, round bales had been fed by using a cone feeder (Fig. 2 ). The surface area covered by hay residues and considered as potential larval habitat for each feeding site was estimated with a 25-m measuring tape. From 17 May through 25 June 2001, these sites were periodically inspected for the presence of fly larvae, as determined from subtle changes in the medium surface (loose material). When larvae were found, core samples 25 by $25 \mathrm{~cm}$ and $5-8 \mathrm{~cm}$ in depth were collected with a pitchfork and a spade. Two core samples were obtained from each site and placed in 25 by 25 by 30 -cm-tall plastic tubs with lids affixed with two screen cones and cups to collect emerging flies. Buckets were kept in a greenhouse until all flies emerged, after which the number of stable flies was recorded. To evaluate stable fly emergence from these samples as a function of time of summer, numbers of emerged flies during three periods, 17-25 May, 29 May-7 June, and 13-25 June were compared by the GLM procedure (SAS Institute 1999). Data were log-transformed because the variances were not homogeneous.

In addition to the nine winter feeding sites around Manhattan, similar sites were used in pastures near Hutchinson, Reno County, Kansas. Conventional tub or ring feeders had been used in all of these sites. Populations of stable flies in the pastures near Manhattan and Hutchinson during spring and summer 


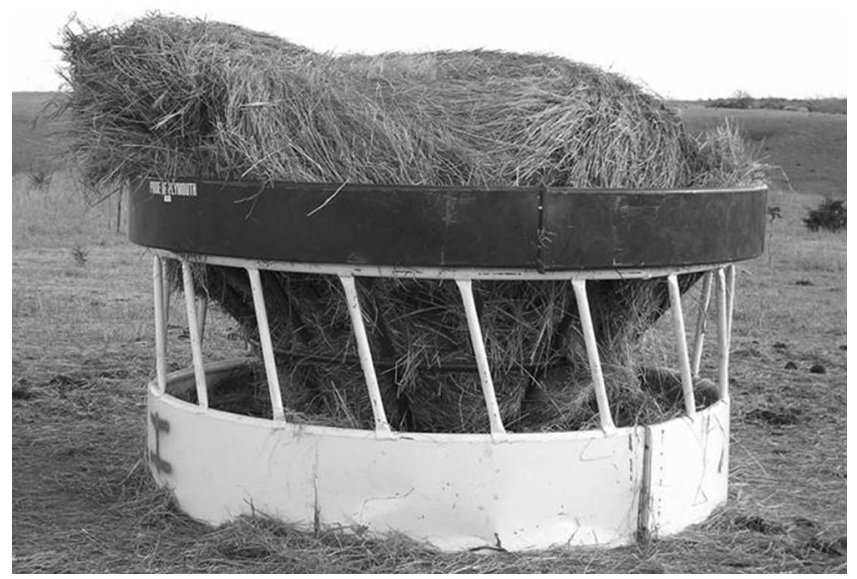

Fig. 2. New cone type of round bale feeder.

2001 were monitored with alsynite cylinder traps (Broce 1988). Some of these traps were placed within $50 \mathrm{~m}$ of the hay feeding sites (NEAR), whereas others were located at least $0.5 \mathrm{~km}$ (FAR) from these feeding sites. Attempts were made to protect most traps from cattle, either by existing fences or by installing electric fences (Zareba, Rochester, MN) around the traps. Sticky sleeves on all traps were changed on the same day twice weekly (every 3 to $4 \mathrm{~d}$ ), and the number of stable flies per trap was recorded. There were six and nine trap pairings in Manhattan and Hutchison, respectively. The numbers of stable flies caught by pairs of NEAR and FAR traps within a pasture (site) were compared by the GLM procedure (SAS Institute 1999). In addition, trap captures at NEAR versus FAR sites for all sets of trap pairs in Manhattan and in Hutchinson were analyzed for correlation.

Alsynite cylinder traps also were operated during summer 2002, 2003, and 2004 at eight of the same sites as in 2001. Again, the sticky sleeves were changed twice per week. Stable fly captures by these traps during the different summers were compared. Because operation of traps during 2001 did not start until 30 May, comparisons were not performed except for captures made during the 30 May through 30 June period. Average fly captures for that sampling period, expressed as stable flies per trap per day, were regressed against monthly mean temperatures and rainfall for the preceding months (PROC CORR., SAS 1999). Likewise, correlation analyses were performed of the average fly captures as a function of minimum and mean monthly temperatures for the November through February of the preceding winter (during the bulk of the hay-feeding season), because the perception exists that ranchers feed more hay as winter temperatures drop.

In an attempt to document the movement of stable flies from the winter hay-feeding sites to other pastures, two mark-release-recapture experiments were conducted. Hay-feeding sites were inspected for larval populations. Larvae were collected by hand, taken to the laboratory, and allowed to pupate in clean sand. To estimate the number of flies marked and released, three 38 -g samples of pupae were placed in 30 by 30 by $30-\mathrm{cm}$ screened fly cages, and flies were allowed to emerge. Flies subsequently were counted, and an average number of flies per gram of pupae was calculated. To mark the flies, pupae were placed on the bottom of 22.5 by $22.5-\mathrm{cm}$ aluminum pans and covered with a $2.5-\mathrm{cm}$ layer of wheat bran mixed with fluorescent powder (Day-Glo Color Corp., Cleveland, $\mathrm{OH})$ at the rate of 1 liter of bran:150 $\mathrm{ml}$ of powder. Pupal containers were placed in fly cages and kept in a fly rearing room $\left(25 \pm 2{ }^{\circ} \mathrm{C}, 70 \pm 10 \% \mathrm{RH}\right.$, and a photoperiod of 18:6 [L:D] h) until flies began to emerge. As flies emerged and crawled through the bran, they marked themselves with the fluorescent powder. Fly cages with adults and pupae were taken to winter feeding sites to allow flies to escape for the 3-d periods indicated: GA (28-30 June), CC1 (28-30 June), and CC2 (3-5 July); a different color of marking powder was used each time. Adhesive-coated sleeves from cylinder traps operated around Manhattan were observed under UV light for detection of marked flies.

\section{Results and Discussion}

The numbers of stable flies emerging from the core samples of residues at hay-feeding sites were highly variable among the different sites and ranged from 102 to 1,225 per $0.0625 \mathrm{~m}^{2}$ ( 25 by 25 -cm core samples; Table 1). The surface area covered by the accumulated hay residues and manure ranged from 13 to 262 $\mathrm{m}^{2}$. It was evident that the larger sites were created by the practice of repeatedly placing the round bale feeders at the same site. At some of the sites, the mixture of hay residues, manure, and soil was $25 \mathrm{~cm}$ in depth. The maximum depth at which media were suitable for larval development was not determined.

The means for the numbers of flies from three sampling periods-17-25 May, 29 May-7 June, and 13-25 June-were 162.7, 38.3, and 8.9 flies (log means), re- 
Table 1. Total number of stable flies that emerged from 25 by $25-\mathrm{cm}$ core samples (and per square meter) of larval habitats at winter feeding sites of hay in round bales, and surface area covered by accumulated residues (Kansas, spring and summer 2001)

\begin{tabular}{|c|c|c|c|c|}
\hline \multirow{2}{*}{ Site } & \multirow{2}{*}{ No. samples } & \multicolumn{2}{|c|}{ Emerged flies } & \multirow{2}{*}{ Area $\left(\mathrm{m}^{2}\right)$} \\
\hline & & Total & $/ \mathrm{m}^{2^{a}}$ & \\
\hline NI & 7 & 1,025 & 2,343 & 178 \\
\hline $\mathrm{CO}$ & 5 & 1,225 & 3,920 & 82 \\
\hline $\mathrm{PH}$ & 5 & 1,062 & 3,398 & 22 \\
\hline PT & 4 & 862 & 3,448 & 13 \\
\hline DI & 11 & 450 & 654 & 262 \\
\hline FI & 4 & 161 & 644 & 22 \\
\hline $\mathrm{SC}$ & 12 & 194 & 287 & 63 \\
\hline WZ & 11 & 103 & 150 & 22 \\
\hline GA & 10 & 102 & 163 & 27 \\
\hline
\end{tabular}

${ }^{a}$ Number of emerged stable flies, estimated per square meter, based on the number of core samples taken.

spectively, and all values were significantly different $(P<0.05$ level; log least significant difference [LSD] $=0.493)$. Results indicated that fly production diminished as the summer progressed, most likely because of higher temperatures and lower rainfall, making these habitats unsuitable for stable fly larval development.

Numbers of stable flies captured in FAR traps were compared with number of flies captured in NEAR traps operated under the same schedule; only six and nine pairs could be used in Manhattan and Hutchinson, respectively, because of logistic constraints. In four of the six trap pairs in Manhattan, the numbers of stable flies caught on NEAR traps were significantly greater than the numbers of flies caught on the corresponding FAR traps (Table 2). In Hutchinson, in four of the nine trap pairings, the NEAR captures were significantly greater than those of FAR traps (Table 2). It is surprising that, in one of the trap pairs (CL1-2), the FAR trap captures were significantly greater than those at the NEAR trap. A correlation analysis of fly captures at NEAR and FAR traps for the entire set of trap pairings in Manhattan resulted in an $r$ value of 0.450; whereas a similar analysis for the Hutchinson data resulted in a much lower value of 0.040 .

The number of flies trapped during the $30 \mathrm{March}-30$ June periods in 2001-2004 followed similar patterns (Fig. 3). Thus, the populations of 2002, 2003, and 2004 all peaked during the week centered on 2 June, albeit at different levels. The 2001 population peaked $1 \mathrm{wk}$ earlier. The populations of 2001 and 2003 showed second population increases, although just $10 \%$ of those in the first peaks, during September and October; both increases peaked during 7-21 October. Numbers of trapped flies during fall 2004 and 2002 were very small, just fractions of a fly per trap per $d$. These population changes followed patterns considered by Greene (1989) to be typical of areas in the midwestern United States.

Correlation analyses of the mean number of captured flies during the 30 May-30 June period of the four summers and the mean and minimum temperatures and rainfall during the preceding months (March, April, May, March-May, and April-May) indicated no significant relationship (data not shown) with the spring rainfall and temperature values; however, fly captures during May through June correlated significantly with the minimum temperatures during the December through February and November through February periods $(F=16.52$ and 85.66 ; $\mathrm{df}=$ 1,$2 ; P<0.055$ and 0.011 , respectively) of the preceding winter, supporting the supposition that cattle producers increase the amount of hay supplied to cattle as temperatures drop. These increases in supplied hay are accompanied by increases in the amount of hay wasted, which serves as stable fly larval medium during the following spring through summer.

No marked stable flies were recaptured from the 4,827 released at CC2. The daily mean wind directions during this release were 220,70 , and $120^{\circ}$. One fly was recaptured from each of the releases made at GA and $\mathrm{CCl}$ at which 3,680 and 4,650 flies were released, respectively. These recaptured flies had traveled 3.46 and $3.06 \mathrm{~km}$ westward from their release points. The daily mean wind directions during the three release days were 120,140 , and $180^{\circ}$. Although only two flies were recaptured from the 13,157 flies released (a not uncommon ratio in other fly dispersal studies), in an area where 11 other traps were located from 1.54 to $3.54 \mathrm{~km}$ from the release points, these results demonstrate that stable flies developing in winter hay residues do disperse to other pastures.

Table 2. Mean numbers of stable flies per trap per day on alsynite cylinder traps NEAR $(\approx 50 \mathrm{~m})$ and FAR $(>0.5 \mathrm{~km})$ from round hay bale feeding sites near Manhattan and Hutchinson, KS (spring and summer 2001)

\begin{tabular}{|c|c|c|c|c|c|c|c|c|c|}
\hline \multicolumn{5}{|c|}{ Manhattan } & \multicolumn{5}{|c|}{ Hutchinson } \\
\hline Trap pairs & $n$ & NEAR & FAR & LSD & Trap pairs & $n$ & NEAR & FAR & LSD \\
\hline SC-DB & 9 & 1009.6 & 62.3 & $332.5^{*}$ & LL1-2 & 5 & 161.2 & 32.2 & $96.3 *$ \\
\hline CI-CO & 11 & 699.7 & 217.4 & $476.8^{*}$ & LL3-4 & 4 & 32.0 & 14.7 & 31.3 \\
\hline CI-XM & 7 & 1002.1 & 241.1 & $652.9^{*}$ & SAl-2 & 4 & 132.4 & 121.9 & 127.1 \\
\hline FI-XN & 13 & 357.5 & 132.6 & $201.5^{*}$ & SOl-2 & 5 & 32.5 & 33.4 & 26.3 \\
\hline WZ-SH & 6 & 188.5 & 165.2 & 161.7 & RW1-2 & 5 & 230.9 & 29.5 & $107.0^{*}$ \\
\hline \multirow[t]{4}{*}{ DI-LT } & 10 & 217.7 & 144.2 & 123.9 & $\mathrm{CLl}-2^{a}$ & 5 & 81.3 & 417.2 & $240.6^{*}$ \\
\hline & & & & & $\mathrm{HCl}-2$ & 4 & 96.6 & 187.9 & 126.9 \\
\hline & & & & & OW1-2 & 5 & 135.1 & 23.0 & $41.1^{*}$ \\
\hline & & & & & OZ1-2 & 5 & 213.4 & 145.5 & 112.0 \\
\hline
\end{tabular}

\footnotetext{
* Statistical differences exist between the NEAR and FAR trap captures at the $P<0.05$ level, with means separated by LSD.
}

${ }^{a}$ FAR trap caught significantly more than did the NEAR trap. 


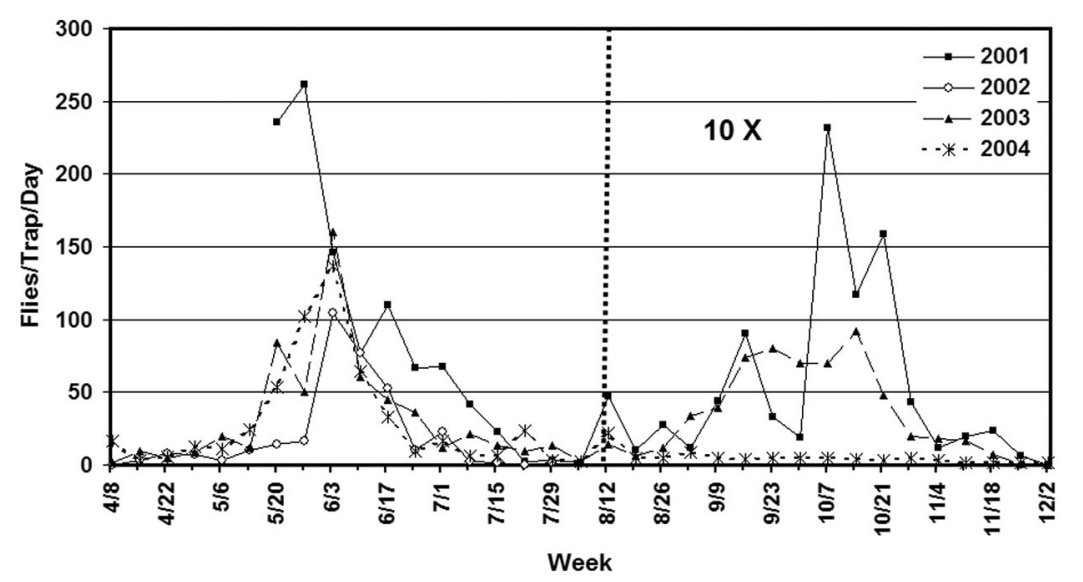

Fig. 3. Average number of stable flies caught daily on cylindrical alsynite traps in Riley County, KS, during 2001 through 2004. Values after 5 August are magnified 10×.

Results of this study indicate that these winter feeding sites of hay in round bales become excellent larval developmental habitats months later in the spring and summer. The source of the colonizing flies is unknown, but they would have to be either flies that have overwintered in CAFO and subsequently have dispersed into these pasture habitats, or flies that migrate from southern regions, riding on the warm southerly winds in association with the approach of spring cold fronts (A.B.B. and J.H., unpublished) or both. A trend was observed in more flies being trapped near the winter feeding sites than at more distant locations, further supporting the hypothesis that these feeding sites are the sources of stable flies in pastures. Although the lack of correlation between the number of flies trapped in the NEAR and FAR traps might be puzzling, it could be because of various factors, including the following. 1) The pairing of two particular traps was imperfect in that other hay feeding ground(s) situated closer to the trap pairs may have been undetected and could have made a greater contribution to the flies caught on the FAR traps. 2) The large degree of stable fly dispersal (for review, see Broce 1993) could have erased any possible correlation between two traps separated by a short distance of $0.5 \mathrm{~km} .3$ ) The topography of the study area (the Flint Hills) may have channeled the flies' dispersal in unexpected ways.

Results of this study suggest that the increase of stable flies in pastures correlates with the adoption of the large hay bale technology, which is used on most pasture beef cattle operations in the midwestern United States. At these winter feeding grounds, considerable residue remains. The mixing of hay, urine, manure, and rain results in a variety of microhabitats that are readily exploited by the larvae (Hogsette et al. 1987). It has been estimated that $25-30 \%$ of the hay is wasted when it is rolled out, or fed, on the ground. Blasi et al. (1993) estimated that rolling out round bales on the ground resulted in 22 and $23 \%$ wastage for wheat hay and hybrid Sudan hay, respectively. Buskirk et al. (2003) found that rolled hay losses ranged from
11.4 to $14.6 \%$ with trailer and cradle type feeders, whereas losses of alfalfa hay from ring and cone-type feeders could be as low as $3.5-6.1 \%$ when fed on a concrete surface. All of these situations may develop into ideal larval habitats.

In the feeding trials of Ball et al. (1998), feeding losses ranged from $<2 \%$ when great care was exercised to $>60 \%$ when no attempts were made to reduce loss. These authors considered feeding losses of 3-6\% to be acceptable in most feeding programs, but such small amounts of waste could only be attained under conditions requiring high labor inputs and frequent feeding. Whether feeding grounds with a $6 \%$ wastage of hay develop into suitable fly larval habitats remains to be investigated.

There are currently no effective methods for the management of stable flies attacking pastured livestock. Insecticide sprays on the legs of cattle result in only temporary (few days) relief because the residues are removed by vegetation wet by early morning dew (Campbell and Hermanussen 1971). Dust bags, oilers, and ear tags are ineffective because they fail to treat the belly and legs of cattle. Feed additives are also ineffective because stable flies develop only in old manure (Broce and Haas 1999), where larvicide residues are degraded. Cultural control (i.e., sanitation) is the most important method for on-site reduction of stable fly populations (Greene 1993). Foil and Hogsette (1994) recommended that if large hay bales being fed to stock were placed on wagons (or other mobile platforms), residue accumulations could be minimized by moving the wagons a short distance once or twice a week. The amounts of hay and feces deposited over a given area are small and tend to dry completely, without becoming attractive oviposition sites in the spring and summer. Removing residues from feeding grounds and spreading on cropland in the spring is seldom practiced in the midwestern United States because rainfall increases at this time of the year, making the operation difficult. The large populations of stable flies on the range can also be relevant to water pollution, as attacked cattle are 
forced into water, and bovine feces and urine deposited directly into water have a greater impact on water quality than do wastes landing on grounds near or away from the body of water.

It is unknown yet to what extent the reduction of the amount of hay wastage affects the development of larval habitats in pastures. Cone-type feeders seem to be the best for waste reduction, but they cost 3 to 4 times more than single tubs. Routine removal of hay residues might be a costly operation and be required at a time when the producer is occupied in other ranching chores. In addition, the residues would have to be removed during early spring, which often is the wettest time of the year, making the removal difficult.

It is clear that evaluation of different feeding methods and cost-benefit analysis in relation to the production of stable fly habitats is needed. Moreover, identification of alternative control strategies, including laboratory and field testing of potential chemical and biological insecticides, is essential for an effective management of stable flies in the pastured cattle habitat.

\section{Acknowledgments}

We thank Kent Hampton and Justin Talley (Department of Entomology, Kansas State University) for assistance during this study and manuscript preparation. This study is Contribution no. 05-290-J from the Kansas Agricultural Experiment Station. This research was supported in part by Hatch Project KAN564 and by regional projects S-274 and S-1005.

\section{References Cited}

Ball, D., D. Bade, G. Lacefield, N. Martin, and B. Pinkerton. 1998. Minimizing losses in hay storage and feeding. Natl. Forage Inf. Cir. 98-1. Graphics Center, Sacramento, CA.

Blasi, D. A., R. K. Taylor, G. W. Warmann, B. M. Plaschk, and G. E. Newdigger. 1993. Large round bale hay wastage by various feeding methods; pp 46-48. In Cattlemen's Day 1993, Rep. Prog., Kans. Agric. Exp. Stn., Manhattan, KS.

Broce, A. B. 1988. An improved alsynite trap for stable flies, Stomoxys calcitrans (Diptera: Muscidae). J. Med. Entomol. 25: 406-409.

Broce, A. B. 1993. Dispersal of house flies and stable flies. In G. D. Thomas and S. R. Skoda [eds.], Rural flies in the urban environment. North Central Regional Res. Publ. No. 335, University of Nebraska, Lincoln.

Broce, A. B., and M. S. Haas. 1999. Relation of cattle manure age to colonization by stable fly and house fly (Diptera: Muscidae). J. Kans. Entomol. 72: 60-72.

Bruce, N. W., and G. C. Decker. 1958. The relationship of stable fly abundance to milk production in dairy cattle. J. Econ. Entomol. 51: 269-274.
Buskirk, D. D., A. J. Zanella, T. M. Harrigan, J. L. Van Lente, L. M. Gnagey, and M. J. Kaercher. 2003. Large round bale feeder design affects hay utilization and beef cow behavior. J. Anim. Sci. 81: 109-115.

Campbell, J. B., and J. F. Hermanussen. 1971. Efficacy of insecticides and methods of insecticidal application for control of stable flies in Nebraska. J. Econ. Entomol. 54: 1189-1190.

Campbell, J. B., R. G. White, R. Croosshank, and D. C. Clanton. 1977. Effects of stable flies on weight gains and feed efficiency of calves on growing or finishing rations. J. Econ. Entomol. 70: 592-594.

Campbell, J. B., I. L. Berry, D. J. Boxler, R. L. Davis, D. C. Clanton, and G. H. Deutscher. 1987. Effects of stable flies (Diptera: Muscidae) on weight gain and feed efficiency of feedlot cattle. J. Econ. Entomol. 80: 117-119.

Campbell, J. B., S. R. Skoda, D. R. Berkebile, D. J. Boxler, G. D. Thomas, D. C. Adams, and R. Davis. 2001. Effects of stable flies (Diptera: Muscidae) on weight gain of grazing yearling cattle. J. Econ. Entomol. 94: 780-783.

Foil, L. D., and J. A. Hogsette. 1994. Biology and control of tabanids, stable flies and horn flies. In Ectoparasites of animals and control methods. Rev. Sci. Tech. Off. Int. Epiz. 13: 1125-1158.

Greene, G. L. 1989. Seasonal population trends of adult stable flies, pp 12-17. In J. J. Petersen and G. L. Greene [eds.], Currents status of stable fly (Diptera: Muscidae) research. Misc. Publ. Entomol. Soc. Am. 74: 12-17.

Greene, G. L. 1993. Chemical, cultural, and mechanical control of stable flies and house flies. In G. D. Thomas and S. R. Skoda [eds.], Rural flies in the urban environment. North Central Regional Res. Publ. No. 335. University of Nebraska, Lincoln.

Hall, R. D., G. D. Thomas, and C. E. Morgan. 1982. Stable flies, Stomoxys calcitrans (L.), breeding in large round hay bales: initial associations (Diptera: Muscidae). J. Kans. Entomol. 55: 617-620.

Hogsette, J. A., J. P. Ruff, and C. J. Jones. 1987. Stable fly biology and control in northwest Florida. J. Agric. Entomol. 4: 1-11.

Meyer, J. A., and J. J. Petersen. 1983. Characterization and seasonal distribution of breeding sites of stable flies and house flies (Diptera: Muscidae) on Eastern Nebraska feedlots and dairies. J. Econ. Entomol. 76: 103-108.

Patterson, R. S., and P. B. Morgan. 1986. Factors affecting the use of an IPM scheme at poultry installations in a semitropical climate. In R. S. Patterson and D. A. Rutz [eds.], Biological control of muscoid flies. Misc. Publ. Entomol. Soc. Am. 61: 101-107.

SAS Institute. 1999. SAS user's guide. SAS Institute, Cary, NC.

Skoda, S. R., G. D. Thomas, and J. B. Campbell. 1991. Developmental sites and relative abundance of immature stages of the stable fly (Diptera: Muscidae) in beef cattle feedlot pens in eastern Nebraska. J. Econ. Entomol. 84: 191-197.

Received 16 June 2005; accepted 7 September 2005. 